\title{
Pemberdayaan Perempuan Melalui Peningkatan Agroindustri Kecil Olahan Ubi Jalar (Studi Desa Renah Alai Kecamatan Jangkat Kabupaten Merangin)
}

\author{
Siti Hodijah ${ }^{1 *}$, Parmadi ${ }^{2}$, Dwi Hastuti ${ }^{3}$, Candra Mustika ${ }^{4}$, Syafi $^{\prime}{ }^{5}$ \\ 1,2,3,4,5) Prodi Ekonomi Pembangunan, Fakultas Ekonomi dan Bisnis, Universitas Jambi \\ \begin{tabular}{|l|l|l|l|} 
Diterima: 23-11-2021 & Direvisi: 13-12-2021 & Disetujui: 22-12-2021 & Dipublikasi: 31-12-2021 \\
\hline
\end{tabular}
}

\begin{abstract}
The development of local agricultural and plantation products is carried out through enhancing women's business motivation, awareness, knowledge, and skills by using appropriate technology. This is inextricably linked to women's participation, role, and status in the family. Creativity will increase as a result of their skills, allowing them to boost family income. Women's empowerment is supposed to develop their potential to contribute to the family economy and improve welfare. In addition, diversifying products, as well as creating labeling and packaging for the product, can help to empower communities, particularly women. The methods used in achieving PPM goals include: 1) Formation of a group of women fostering agro-industry, 2) Persuasive, 3) Educational, 4) Participatory, and 5) Normative. Women's empowerment in agro-industry management is projected to boost the added value of sweet potatoes, which could see a price drop during harvest season. It is also intended to increase women's income and family well-being, particularly in Renah Alai Village. Overall, the rise of agro-tourism with diverse products typical of Renah Alai Village can be encouraged by the development of agro-industry.
\end{abstract}

Keywords: women empowerment, business motivation, agroindustry

\begin{abstract}
Abstrak
Pengembangan produk lokal pertanian dan perkebunan dilakukan dengan meningkatka motivasi usaha, kesadaran, pengetahuan, dan keterampilan perempuan dengan penggunaan teknologi yang tepat guna. Hal ini tidak terlepas dari partisipasi, peran, dan posisi perempuan dalam keluarga. Dengan keterampilan yang dimiliki, kreatifitas akan meningkat sehingga mereka dapat meningkatkan pendapatan keluarga. Pemberdayaan perempuan diharapkan dapat mengembangkan potensi yang dimiliki untuk membantu ekonomi keluarga dan meningkatkan kesejahteraan. Selain itu, pemberdayaan masyarakat terutama perempuan dapat dilakukan dengan membuat diversifikasi olahan, serta pembuatan label dan kemasan suatu produk. Metode pengabdian yang digunakan dalam pencapaian tujuan PPM antara lain: 1) Pembentukan kelompok perempuan pembina agroindustri, 2) Persuasif, 3) Eduakatif, 4) Partisipatif, dan 5) Normatif. Pengembangan perempuan dalam pengelolaan agroindustri diharapkan dapat meningkatkan nilai tambah ubi jalar yang kemungkinan mengalami penurunan harga saat musim panen. Selain itu diharapkan dapat meningkatkan pendapatan perempuan dan kesejahteraan keluarga khususnya di Desa Renah Alai. Secara keseluruhan, pengembangan agroindustri dapat mendorong pertumbuhan agrowisata dengan aneka olahan makanan khas Desa Renah Alai.
\end{abstract}

Kata kunci: pemberdayaan perempuan, motivasi usaha, agroindustri

\footnotetext{
* Penulis korespondensi

Email: sitihodijah@unja.ac.id
} 


\section{Pendahuluan}

Sinergitas antara pembangunan pertanian dan pembangunan wilayah pedesaan bertujuan untuk meningkatkan taraf kehidupan sosial dan ekonomi masyarakat (Suyitman, dkk., 2019). Salah satu cara untuk meningkatkan taraf kehidupan masyarakat yaitu melalui strategi bisnis yang dapat menciptakan peluang usaha dalam kegiatan ekonomi pedesaan. Kemudian hal ini akan meningkatkan pendapatan dankesejahteraan masyarakat desa (Syahza, 2003). Desa Renah Alai merupakan kawasan strategis pertanian yang menyediakan kebutuhan pokok masyarakat. Sehingga desa ini memiliki potensi dalam pengembangan produk-produk olahan pertanian. Pengembangan produk lokal pertanian dan perkebunan dilakukan dengan meningkatkan motivasi usaha, kesadaran, pengetahuan, dan keterampilan masyarakat dalam penggunaan teknologi yang tepat guna (Widyasanti, 2016)

Pengolahan bahan pangan lokal dapat diberdayakan oleh perempuan yang akan mendorong pengembangan produk diversifikasi produk dan terbentuknya kemandirian masyarakat. Selain itu, usaha bersama akan memberikan perolehan penghasilan tambahan bagi keluarga (Nurdewanto, dkk. 2015; Nurlaili \& Muhartono, 2017). Hal ini juga diungkapkan oleh Yulistria, dkk. (2020) yang menyatakan bahwa dengan pemberdayaan perempuan diharapkan dapat mengembangkan potensi yang dimiliki dalam membantu ekonomi keluarga dan meningkatkan kesejahteraan. Program pemberdayaan perempuan dimulai pada tahap perencanaan, pelaksanaan, pengambilan manfaat, dan evaluasi program pemberdayaan masyarakat (Komariah, dkk., 2015). Hal ini sejalan dengan pemberdayaan perempuan berbasis ekonomi kreatif melalui pelatihan dalam peningkatan pengetahuan, peningkatan keterampilan, dan peningkatan sikap warga belajar (Hidayat, dkk., 2018; Yati, 2018). Pemberdayaan masyarakat dengan basis pertanian dilakukan karena sebagian besar masyarakat bekerja di sektor pertanian. Strategi pelaksanaan pembangunan pertanian pedesaan harus dirancang dengan sistem agribisnis yang melibatkan beberapa lembaga dan penunjang seperti pengkreditan, pengusaha, petani, dan koperasi (Syahza, 2003). Menurut Nurlaili \& Muhartono, 2017, peran perempuan sangat besar sehingga kegiatan pemberdayaan harus melibatkan perempuan. Pemberdayaan ini dilakukan agar perempuan menjadi mandiri dan dapat membina keluarga dengan baik. Membentuk kelompok-kelompok agroindustri pangan juga disertai dengan pendampingan ke pengrajin dan dilakukan secara terus menerus dengan melibatkan institusi terkait (Istiyanti, dkk., 2018). Hal ini juga diungkapkan oleh Yulistria, dkk. (2020) yang menyatakan bahwa dengan dukungan keterpaduan baik instansi daerah maupun lembaga-lembaga masyarakat (civil society), swasta dan lembaga pendidikan dapat mengoptimalkan pemberdayaan perempuan dalam meningkatkan ekonomi rumah tangga atau keluarga.

Target yang dicapai dalam pengembangan agroindustri ubi jalar adalah bahan olahan ubi jalar menjadi dodol, stick ubi, tepung, kerupuk, dll. Bahan baku ubi jalar dioptimalkan menjadi bahan dengan daya tahan lama dan memiliki nilai tambah ekonomi sehingga harga ubi jalar tidak jatuh dan justru merugikan petani. Target selanjutnya adalah mendukung peningkatan pariwisata dari segi jajanan khas Desa Renah Alsi. Selama ini, komoditas ubi jalar langsung di jual dari petani ke pasar atau distributor. Dengan kata lain, ubi jalar belum diolah masyarakat Desa Renah Alai menjadi sebuah produk lain. Oleh karena itu, perlu pengembangan agroindustri untuk mencegah harga anjlok saat musim panen datang dan resiko ubi jalar mudah busuk, dan lain sebagainya. 


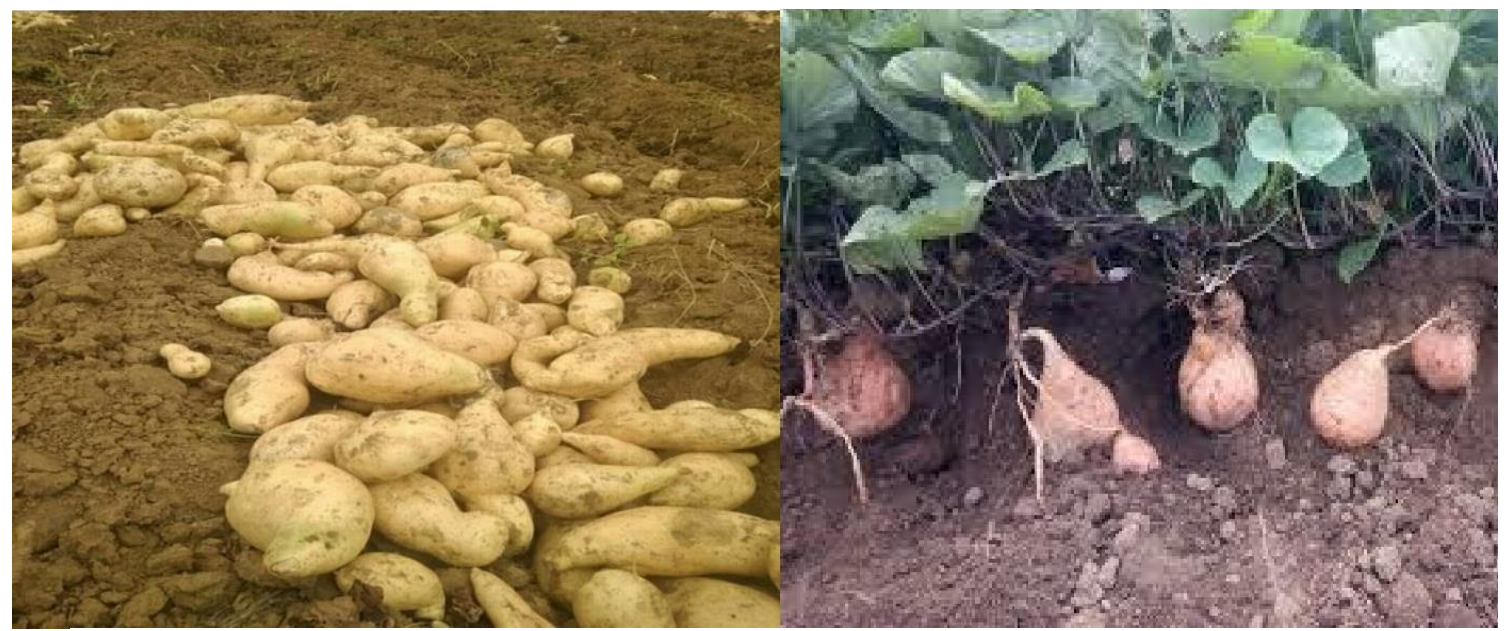

Gambar 1. Panen Ubi Jalar

Berdasarkan potensi sumber daya alam yang dapat dijadikan produk olahan dengan nilai tambah (value added), maka hal ini menjadi salah satu topik utama dalam pengabdian. Upaya pemberdayaan masyarakat diharapkan mampu secara mandiri memanfaatkan potensi daerahnya, salah satunya dengan pengetahuan dan keterampilan mengenai wirausaha dan teknologi tepat guna (Widyasanti, 2016). Dengan demikian, peran perempuan akan sangat besar dalam pemberdayaan perempuan melalui kegiatan bertema "Pemberdayaan Perempuan melalui Peningkatan Agroindustri Kecil Olahan Ubi Jalar (Studi Desa Renah Alai Kecamatan Jangkat Kabupaten Merangin)”.

\section{Rumusan masalah}

Ketidakstabilan ekonomi di masa pandemi Covid-19 menjadi tantangan yang cukup sulit dalam meningkatkan pertumbuhan ekonomi. Perlu upaya dalam meningkatkan ekonomi masyarakat misalnya dengan meningkatkan potensi sumber daya dan SDM masyarakat. Selain itu, dapat dilakukan peningkatan kualitas SDM, kemudahan mendapatkan perizinan, sistem perkreditan yang mempermudah UMKM untuk mendapatkan modal, serta menyediakan sarana pemasaran dan informasi pasar (Situmorang, 2015). Permasalahan yang ada di masyarakat dapat diatasi melalui pemberdayaan masyarakat terutama perempuan dan pemuda yang tidak bekerja dengan melakukan diversifikasi olahan, pembuatan label dan kemasan, serta pembuatan website yang akan menambah daya jual produk (Indrawati, dkk., 2018). Pemberdayaan ekonomi perempuan dapat dilakukan dengan pembentukan kelompok Usaha Kecil Menengah (UKM), penguatan kapasitas, dan pengembangan usaha (Susilawati, 2019). Pengembangan usaha ini dapat berbasis agroindustri masyarakat dengan potensi lokal masyarakat. Tantangan yang masih dijumpai di daerah yaitu kendala pada segi pendidikan, motivasi berwirausaha, persaingan dan perlindungan usaha yang perlu diperhatikan agar usaha dapat berkelanjutan (Haryono, dkk., 2017). Pengabdian PPM di desa mitra Prodi Ekonomi Pembangunan secara khusus dilakukan untuk menjawab persoalan terkait dengan pemberdayaan perempuan melalui peningkatan agroindustri kecil olahan ubi jalar.

\section{Solusi permasalahan mitra}

Pembangunan wilayah pedesaan bertujuan untuk meningkatkan taraf kehidupan sosial dan ekonomi masyarakat berdasarkan pengembangan kawasan potensial (Suyitman, dkk., 2019). Pengembangan kawasan lokal dapat meningkatkan daya saing dan tercapainya pertumbuhan ekonomi Jawa Timur yang berdaya saing global (Nugroho \& Rusydiana, 2018). Dengan potensi pertanian yang dimiliki suatu daerah, diharapkan dapat memenuhi 
kebutuhan dalam meningkatkan daya saing misalnya dengan pengembangan agroindustri produk turunan dari ubi jalar. Pengembangan agroindustri menggambarkan kemampuan suatu industri dengan mencipatakan nilai tambah suatu produk pertanian atau yang dikenal dengan industri pengolahan hasil pertanian (Hadi, 2015).

\section{Metode Pengabdian}

Pelaksanaan pengabdian PPM Fakultas Ekonomi dan Bisnis UNJA tahun 2021 dilakukan dalam beberapa tahapan, yaitu persiapan, observasi, dan evaluasi. Metode persiapan menggunakan metode focus group discussion (FGD) bersama warga serta observasi lapangan. Metode pelaksanaan dilakukan dengan pembentukan kelompok, ajakan, observasi potensi desa, dan evaluasi kegiatan dalam pemetaan potensi. Sedangkan metode evaluasi dilaksanakan dengan diskusi bersama mitra.

Secara keseluruhan metode penyuluhan pengabdian dilakukan dengan menggunakan metode penyuluhan partisipatif yang diikuti dengan demonstrasi dan praktik (Satrya, dkk., 2019) terdiri dari: 1) Pembangunan komunitas, 2) Persuasif/ajakan, 4) Edukatif, 5) Partisipatif, dan 5) Normatif. Adapun tahapan-tahapan pengabdian kepada masyarakat skema di Desa Renah Alai Kecamatan Jangkat Kabupaten Merangin yang dilaksanakan di Tahun 2021 adalah sebagai berikut:

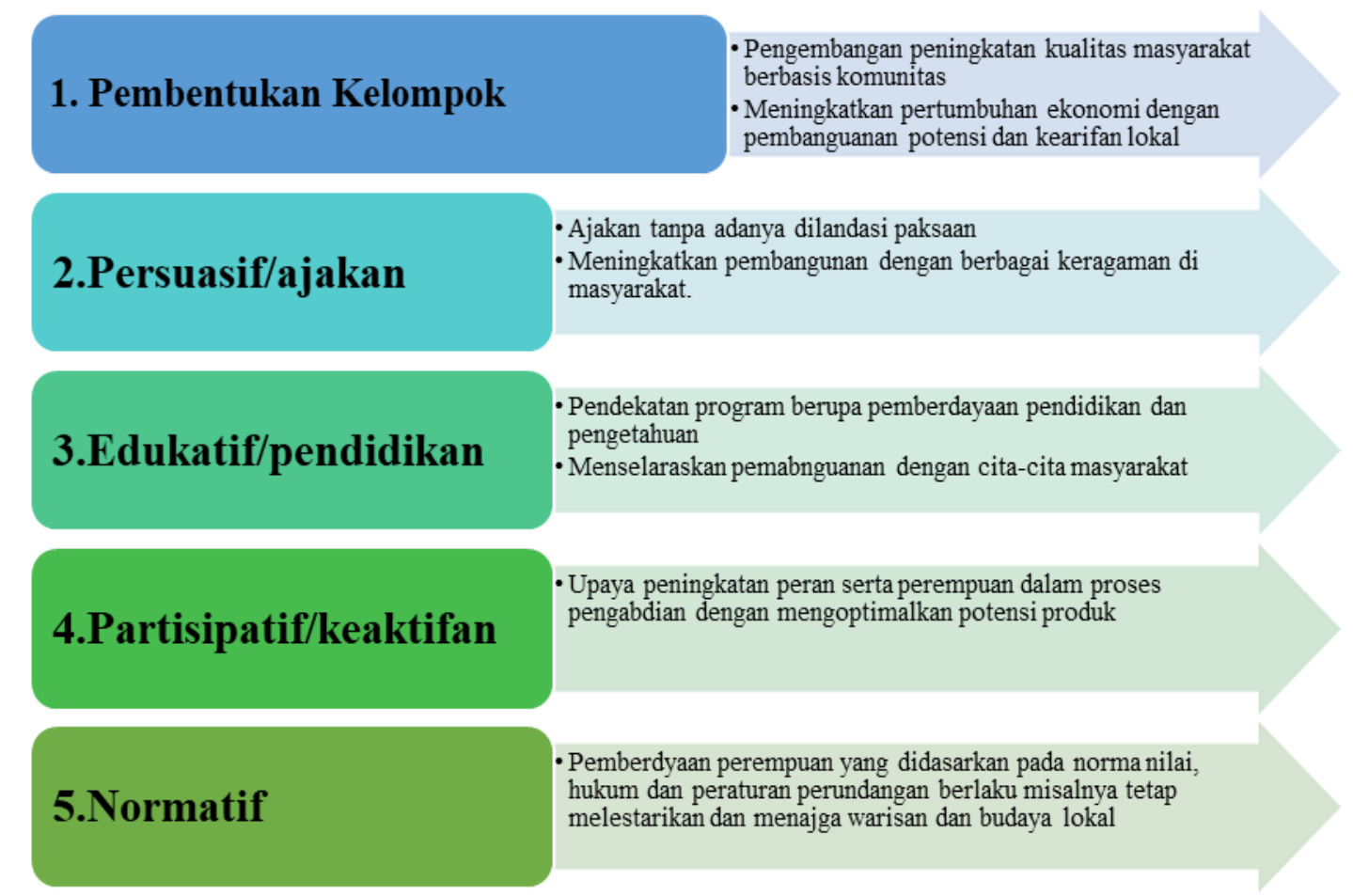

Gambar 2. Metode Pelaksanaan

\section{Pelaksanaan pengabdian PPM 2021}

Pada pelaksanaan tahap ke-2 (dua) pengabdian skema PPM Fakultas Ekonomi dan Bisnis UNJA Tahun 2021 terdiri dari beberapa tahapan yaitu: 1) Survei lokasi penyuluhan PPM pengabdian, 2) Negosiasi mitra atau kerja sama mira, 3) Pendataan kelompok, 4) Penetapan izin lapangan, dan 5) Monotoring dan evaluasi kegiatan. 


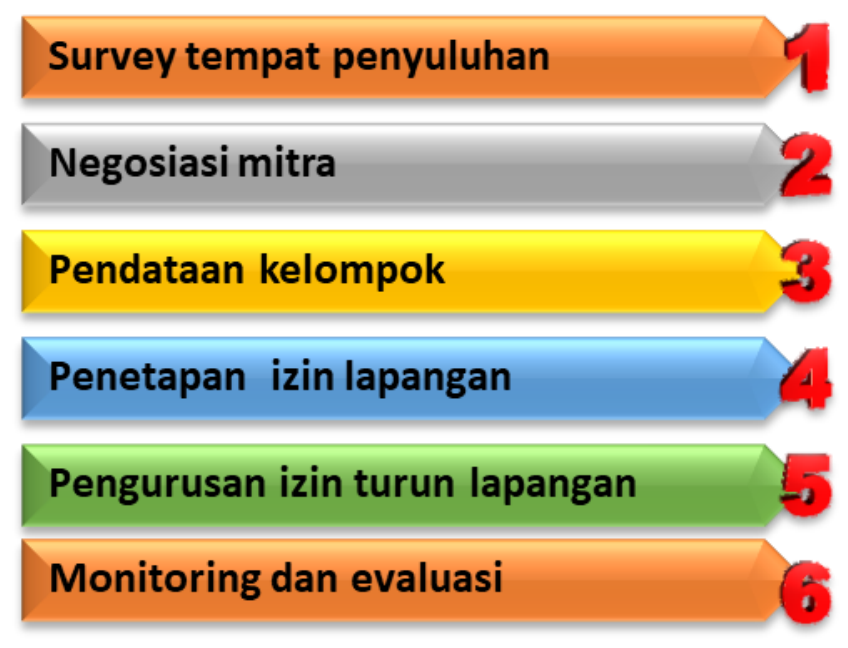

Gambar 3. Tahapan Kegiatan Pengabdian (PPM)

Target yang ingin dicapai pada kegiatan PPM FEB UNJA berupa pelatihan dengan pemberdayaan masyarakat terkait pemanfaatan potensi lokal Desa Renah Alai Kecamatan Jangkat Kabupaten Merangin. Tiga mahasiswa akan membantu kegiatan pengabdian ini. Pelaksanaan Tridarma sebagai dosen di UNJA setiap tahunnya juga membantu mengatasi permasalahan masyarakat, misalnya di Desa Renah Alai. Selain itu, partisipasi mitra juga dibutuhkan dalam pelaksanaan pengabdian ini. Desa Renah Alai sebagai desa mitra menyediakan lokasi pengabdian, serta bekerja sama dalam menyampaikan potensi-potensi desa yang akan dijadikan desa percontohan. Perangkat desa juga berperan untuk melanjutkan pengelolaan website agar potensi-potensi desa selalu diperbaharui.

Tahap evaluasi pengabdian dilakukan dengan melihat perkembangan kemampuan masyarakat lokal sehingga pembangunan UKM dapat berkelanjutan. Jika dalam pelaksanaan mengalami kendala, maka kegiatan akan diperbaiki sehingga program pengabdian kepada masyarakat tepat sasaran, efektif, dan maksimal. Setelah pengabdian selesai, Prodi EP akan tetap melakukan pemantauan dan pendampingan industri olahan Desa Renah Alai ini. Selanjutnya, perlu penguatan agroindustri dengan melibatkan kerja sama dinas terkait dan stakeholder melalui pendampingan berupa tekonologi dan pembinaan lanjutan agar proses produksi menjadi lebih efisen dan tepat guna.

\section{Hasil dan Pembahasan}

Dalam pola pembinaan perempuan di Desa Renah Alai, prinsip dasar yang harus dipahami oleh para pelaku usaha yaitu pemberdayaan masyarakat secara optimal. Dilatarbelakangi oleh potensi yang dimiliki wilayah sekitar Desa Renah Alai, perbaikan infrastruktur dan promosi wisata, maka banyak wisatawan baik lokal dan luar yang berkunjung ke Jangkat. Hal ini memberikan peluang untuk pengembangan ubi jalar seperti stik ubi jalar, keripik ubi jalar, dan lainnya. Keberadaan agroindustri kecil olahan ubi jalar akan diminati oleh perempuan dengan jiwa wirausaha. Program pengabdian ini bertujuan untuk mendorong peran aktif perempuan di Desa Renah Alai Kecamatan Jangkat terkait dengan pengelolaan industri kecil berbasis pertanian ubi jalar.

Pendampingan dilakukan oleh beberapa dosen dari Prodi EP UNJA secara bekerlanjutan di desa binaan Ekonomi Pembangunan dengan pola pendanaan dana pengabdian FEB UNJA. Metode pendampingan berupa pelatihan dan sosialisasi nilai lebih dari produk olahan ubi jalar. Dengan ceramah dan diskusi, serta pelatihan, masyarakat diharapkan paham tentang pangsa pasar, strategi marketing/pemasaran, dan permodalan. Setiap kegiatan dipastikan melibatkan 
mahasiswa dalam kegiatan pengabdian kepada masyarakat ini. Dari pendampingan ini, diharapkan akan tumbuh sentra-sentra produksi UMKM unggulan berdasarkan potensi SDA yang dimiliki.

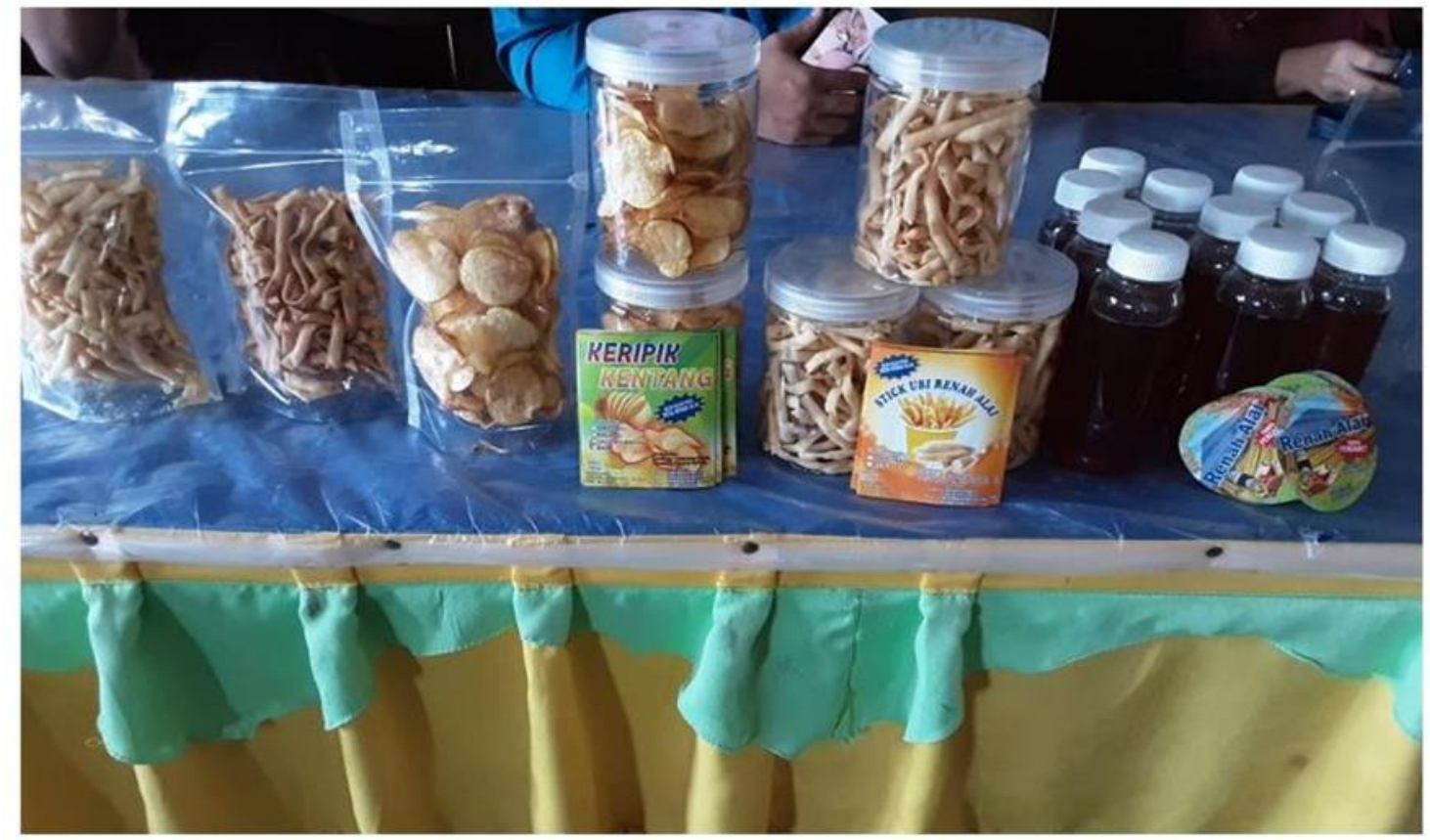

Gambar 4. Olahan Produk Melalui Pemberdayaan Perempuan

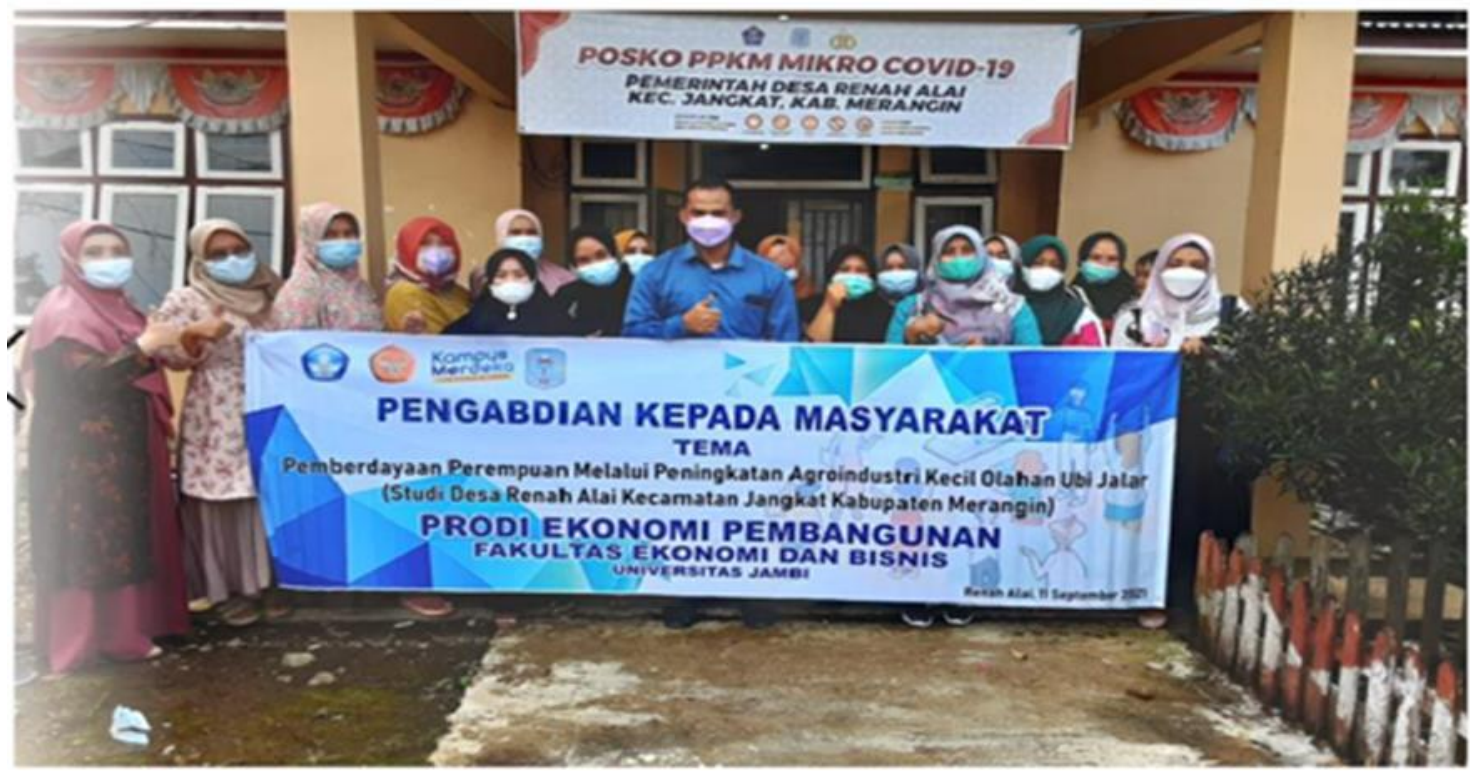

Gambar 5. Foto Bersama Masyarakat, Tim Pengabdian, dan Mahasiswa

\section{Kesimpulan}

\section{Kesimpulan dan Saran}

Kawasan Desa Renah Alai yang berada di Kecamatan Jangkat Kabupaten Merangin merupakan desa yang potensial untuk pengembangan agroindustri kecil olahan produk ubi jalar karena jumlah kunjungan wisatawan lokal dan luar cukup tinggi. Untuk keberlanjutan program pengabdian kepada masyarakat, Prodi Ekonomi Pembangunan FEB UNJA telah melakukan kerja sama dengan Desa Renah Alai sebagai desa binaan atua dampingan, yang mana saat ini terdapat kegiatan 
KKN mahasiswa sehingga produksi dan pengelolaan produk olahan ubi jalar dapat dioptimalkan.

\section{Saran}

Perlu bimbingan Dinas Koperasi dan UMKM, serta Dinas Kebudayaan dan Dinas Pariwisata terkait dengan pengembangan produksi ubi jalar menjadi produk olahan dengan nilai ekonomi yang lebih tinggi sehingga dapat menarik minat pengunjung lokal maupun luar dan menjadikan produk olahan ini sebagai makanan/oleh-oleh khas dari Desa Renah Alai.

Untuk keberlanjutan program pengabdian kepada masyarakat, kedepannya diperkuat dengan peningkatan mutu pegawai dengan mempekerjakan masyarakat sekitar untuk membuka bisnis baru yang menjual produk olahan ubi jalar, terutama perempuan yang tinggal di Desa Renah Alai. Oleh karena itu, harus dilakukan monitoring dan evaluasi terus menerus terhadap perkembangan usaha produk olahan ubi jalar oleh masyarakat desa terutama perempuan desa, sehingga program pengabdian dapat terus mendapatkan penyempurnaan di tahun selanjutnya.

\section{Daftar Pustaka}

Aly, M. N. et al. (2020) 'Pemberdayaan masyarakat melalui program pendampingan desa wisata di Desa Bejijong Kabupaten Mojokerto', Jurnal Layanan Masyarakat (Journal of Public Services). doi: 10.20473/jlm.v4i2.2020.390-399.

Dalimunthe, R. F. \& Lubis, A. N. (2020) 'Pengembangan usaha kecil makanan pada komunitas perempuan di Kecamatan Tanjung Morawa Kota Deli Serdang', Prosiding Konferensi Nasional Pengabdian Kepada Masyarakat dan Corporate Social Responsibility (PKM-CSR). doi: 10.37695/pkmcsr.v3i0.865.

Darmanto \& Sucipto, Y.(2013). Kajian kebijakan (program/penganggaran) penanggulangan kemiskinan perempuan melalui pemberdayaan ekonomi',

Asosiasi Pendamping Perempuan Usaha Kecil.

Hadi, P. (2015) 'Reformasi kebijakan penciptaan nilai tambah produk pertanian Indonesia', Manajemen dan Kinerja Pembangunan Pertanian.

Haryono, A., Natsir, M. \& Suprayitno, A. (2017) 'Peningkatan kompetensi wirausaha melalui perubahan strategi usaha untuk kinerja yang berkelanjutan', in SeminarNasional Sistem Informasi 2017.

Hidayat, S., Djumena, I. \& Darmawan, D. (2018) 'Pemberdayaan perempuan berbasis ekonomi kreatif melalui pelatihan pembuatan keset dari limbah kain', Journalof Nonformal Education and Community Empowerment.

Indrawati, U. S. Y. V., Endang, N. \& Asriati, N. (2018) 'Peningkatan Kemandirian usaha kecil dan menengah melalui pendampingan program KKN-PPM', Buletin Udayana Mengabdi. doi: 10.24843/bum.2018.v17.i03.p04.

Istiyanti, E., Rahayu, L. \& Sriyadi, S. (2018) 'Pengembangan agroindustri pangan lokal melalui peningkatan jaminan mutu pruduk dan pengelolaan keuangan', BERDIKARI : Jurnal Inovasi dan Penerapan Ipteks. doi: 10.18196/bdr.6132.

Komariah, N. et al. (2015) 'Literasi informasi masyarakat pesisir dalam program pemberdayaan perempuan di Kecamatan Cipatujah Kabupaten Tasikmalaya', Jurnal Kajian Informasi dan Perpustakaan. doi: 10.24198/jkip.v3i2.9997.

Nugroho, T. \& Rusydiana, A. S. (2018) 'Mengembangkan agroindustri jawa timur: pendekatan metode analytic network procces', Jurnal Ilmu Ekonomi Terapan.doi: 10.20473/jiet.v3i1.8025.

Nurdewanto, B., Yuniriyanti, E. \& Sudarwati, R. (2015) 'Pemberdayaan perempuan melalui kelompok dasa wiswa PKK', Studi Manajemen dan Bisnis.

Nurlaili, N. \& Muhartono, R. (2017) 'Peran perempuan nelayan dalam usaha perikanan tangkap dan peningkatan ekonomi rumah tangga pesisir teluk jakartA', JurnalSosial 
Ekonomi Kelautan dan Perikanan. doi: 10.15578/jsekp.v12i2.6481.

Satrya, I. D. G., Kaihatu, T. S. \& Pranata, L. (2019) 'Upaya pembinaan masyarakat dalam rangka pengembangan desa ekowisata di dusun mendiro, desa panglungan, kecamatan wonosalam, kabupaten jombang', Jurnal TerapanAbdimas. doi: 10.25273/jta.v4i1.3826.

Situmorang, J. (2015) 'Strategi UMKM dalam menghadapi iklim usaha yang tidak kondusif', Infokop.

Susilawati, S. (2019) 'Pemberdayaan perempuan di "kampung damai": studi pendampingan komunitas oleh wahid foundation di Gemlegan Klaten', JurnalPemberdayaan Masyarakat: Media Pemikiran dan Dakwah Pembangunan. doi: 10.14421/jpm.2018.022-10.

Suyitman, S., Warly, L. \& Hellyward, J. (2019) 'Pengelolaan peternakan sapi potong ramah lingkungan', Jurnal Hilirisasi Ipteks.

Syahza, A. (2003) 'Paradigma baru : pemasaran produk pertanian abstrak pendahuluan', Jurnal Ekonomi.

Widyasanti, A. (2016) 'Upaya pemberdayaan masyarakat melalui pelatihan pembuatan produk sabun berbasis komoditas lokal di Kecamatan Sukamantri Ciamis', Jurnal Aplikasi Ipteks untuk Masyarakat.

Yati, A. (2018) 'Analisis pemberdayaan perempuan melalui simpan pinjam kelompok', Publikauma : Jurnal Administrasi Publik Universitas Medan Area. doi: 10.31289/publika.v6i1.1568.

Yulistria, R., Islami, V. \& Susilawati, S. (2020) 'Pemberdayaan perempuan dan analisa peningkatan ekonomi keluarga melalui program pengembangan industri rumahan kekeba mini', Jurnal Abdimas BSI: Jurnal Pengabdian KepadaMasyarakat. doi: 10.31294/jabdimas.v3i2.8667. 